\title{
Dynamics and functions of the actin cytoskeleton during the plant cell cycle
}

\author{
LIU PeiWei, QI Ming, XUE XiuHua \& REN HaiYun* \\ Key Laboratory of Cell Proliferation and Regulation Biology of Ministry of Education, College of Life Science, Beijing Normal University, \\ Beijing 100875, China
}

Received June 15, 2011; accepted September 5, 2011

\begin{abstract}
In eukaryotic cells, the course of the cell cycle depends on correct cytoskeleton arrangement. The cell cycle consists of several phases, and in each of them the cytoskeleton has a unique structure and set of characteristics. The dynamics of the cytoskeleton together with its binding proteins greatly contribute to progression of the cell cycle. Here, we mainly review recent research on the dynamic distribution of the actin cytoskeleton and actin-binding proteins, and the mechanisms by which they affect the progression of the plant cell cycle.
\end{abstract}

actin cytoskeleton, actin-binding protein, cell cycle, preprophase band, actin-depleted zone, phragmoplast

Citation: Liu P W, Qi M, Xue X H, et al. Dynamics and functions of the actin cytoskeleton during the plant cell cycle. Chinese Sci Bull, 2011, 56: 3504-3510, doi: $10.1007 / \mathrm{s} 11434-011-4801-8$

Every eukaryotic cell goes through many cell cycles to proliferate. A typical cell cycle can be divided into two constitutive phases: interphase and $\mathrm{M}$ phase. Interphase can be subdivided into three phases: $\mathrm{G1}$, in which preparations are made for DNA synthesis; $S$, the DNA replication phase; and $\mathrm{G} 2$, the phase in which the cell prepares for mitosis. M phase consists mainly of mitosis and cytokinesis. Mitosis can be subdivided into prophase, metaphase, anaphase, and telophase. However, there is some overlap between telophase and cytokinesis because it is difficult to divide such a continuous process into discrete steps. The precise mechanisms controlling every phase and the transitions between various phases enable cells to monitor themselves and proliferate accurately. Of the numerous factors that have roles in regulating the cell cycle, the cytoskeleton, including actin filaments or microfilaments (MFs) and microtubules (MTs), acts in every phase, forming different arrays and pushing the cell cycle forward [1,2]. During the cell cycle of higher plant, unique and necessary structures and apparatus formed by the cytoskeleton and its regulators have been identified

*Corresponding author (email: hren@bnu.edu.cn) and characterized in recent years. The results of many studies imply that the arrangement and changes in the cytoskeleton are highly significant for cell proliferation.

The cytoskeleton is more dynamic than its name suggests. As one of the most ancestral, conserved cytoskeleton genes on earth, the gene encoding actin is essential for the survival of most cells. Actin provides mechanical support and movement, functions in intracellular transportation, and maintains the cell cycle $[3,4]$. During a typical cell cycle, actin arrays are constantly changing and rearranging from G1 of one cycle to the G1 phase of the next cycle, pushing the cell cycle forward. Compared with MT arrays in the cell cycle, MF arrays have received less attention. However, according to studies on the effects of inhibitors on MFs, drugs such as Bistheonellide A (BA) that inhibit the polymerization of actin can delay or even halt the cell cycle [5]. Thus, there must be some retrograde signaling in which the state of actin organization affects the progression of the cell cycle. In higher plant cell, many studies on the functions of the actin cytoskeleton during the cell cycle have been carried out using classical cell models, such as the tobacco BY-2 suspension cell line [5-7], cells from different organs of Arabidopsis 
$[8,9]$. Here, we summarize some recent achievements in molecular biology to show how cytoskeleton structures, especially the actin cytoskeleton, control the cell cycle under the regulation of cytoskeleton-binding proteins and some related factors, such as small GTPases.

\section{Dynamics of actin cytoskeleton and its regulation in interphase and prophase}

As mentioned above, research on the cytoskeleton and cell cycle of higher plants has mainly been conducted using the tobacco BY-2 cell line, because it is easy to manipulate and there are well-developed analytical techniques available. In this kind of cell line, there are two types of actin arrays in interphase: in the cortex, a finer meshwork of randomly oriented elements known as cortical MFs form near or in association with the cell membranes [5]; in the cytoplasm, large bundles form deep in the cytoplasm near nucleus and in transvacuolar strands [10]. Some of the bundles link the nucleus to the cortex. In addition, some of MFs form around the nucleus, forming "basket-like" structures [6]. Together, these structures may have a role in holding the nucleus in the correct position in the cytoplasm in interphase, and prepare it for the onset of mitosis. Such preparations include breaking down nuclear membranes and moving chromosomes into the equatorial plane of the cell for correct positioning of the spindle. Depolymerization of actin filaments by toxins such as Cytochalasin D (CD) and Latrunculin B (Lat B) delays the progression of mitosis, suggesting that an intact actin cytoskeleton may be required for the normal mitosis $[11,12]$. When the cell enters into prophase, actin arrays must change to accommodate and facilitate mitosis. The amount of dense interphase cortical microfilaments decreases during this phase, according to findings in BY-2 cells [6]. In late G2 phase, which is also known as preprophase in plant cells, the nucleus enlarges before the nuclear membranes break down. During this process, the chromatin condenses and a band of microtubules known as the preprophase band (PPB) forms in the cortex close to the plasma membrane, encircling the cell equatorially $[13,14]$. Meanwhile, as reported by Eleftheriou et al. [15], the random orientation of MFs that is found throughout the cytoplasm in most interphase cells changes into an arrangement parallel to the PPB in preprophase and prophase cells. Many studies have focused on the changes in MFs and their relationship with the PPB. Take BY-2 cells for example, MFs in the cortex form a band around the PPB, and have a role in narrowing the PPB [13,16]. Myosin motor proteins may also be involved in this process, as most eukaryotes have this gene for the proteins that generate forces on actin filaments [17]. As shown in root tip cells of Allium, the PPB first appears as a wide microtubule band that progressively narrows in mid-prophase. When treated with $\mathrm{CD}$, the PPB fails to narrow and remains at least two-fold wider than control cells [13]. However, different types of cells show different phenomena: MFs in the PPB were prominent in BY-2 cells as mentioned above, but the same structure was not found in Arabidopsis thaliana root cells, even when the same GFP-fimbrin actin-binding domain 2 (GFP-fABD2) MFs reporter was used [18]. This suggests that actin arrays are transient and may form various structures in different cell types, or are visualized differently depending on the observation methods.

The PPB is a marker of the position where the new cell wall will form $[5,13,19]$. During interphase, microtubules are distributed throughout the cell cortex, but at preprophase, they become restricted to the future plane of division via selective depolymerization of non-PPB microtubules [20]. Even though the PPB disappears at the end of late prophase and is not seen again in the cell cycle, the new cell wall still forms at the position where the PPB was once located. However, some evidences prove that the narrowing of PPB might not be decisive in cell wall position determination. As reported by Marcus et al. [21], in cultured tobacco BY-2 cells, PPB microtubules are required for accurate spindle positioning, rather than the position of the plane of division. In his experiment, the reversible anti-microtubule agent Propyzamide was used to depolymerize the PPB before it narrowed and then the agent was removed. As a result, the spindle formed in the wrong position while the new cell wall formed in the position of the PPB as before [21]. This result is possibly because the spindle formation and its axis confirmation needs the microtubules from PPB, and therefore, it was more easily affected by damage of the PPB, while, those factors deciding cell wall position could still be recruited to the previous place of PPB and guide the new cell wall growth [21]. According to this suggestion, PPB microtubules must be downstream factors that could be regulated by other factors decisive in determination of the new cell wall, such as different kinases and phosphatases. If so, there must be some traces of these factors in the location of the PPB. In recent studies, many factors were indeed found to localize with the PPB in preprophase and still be there after PPB degenerate [19,22-25]. For example, In Arabidopsis root cells, the proteins TON and FASS are localized at the site where the PPB is formed [22,24], acting as a base for the formation of the PPB by phosphorylating other factors. PPB microtubules are regulated by microtubule associating proteins (MAPs), which are controlled by phosphorylation and dephosphorylation [26]. TON shows a punctuate pattern of localization at the cortical MT array in hypocotyl cells, and it may act as a MAP [23]. Then, after the PPB initiates, TAN and RanGAP1 are recruited to PPB place $[25,27]$. Those proteins remain at that location (i.e., the cell division zone, CDZ) until cytokinesis, and are maintained via the actions of POK1 and POK2 [28]. RanGAP is the GTPase-activating protein (GAP) of the small 
GTPase Ran (Ras-related nuclear protein). RanGAP greatly accelerates the transformation of Ran from its active status RanGTP to null status RanGDP. RanGAP is conserved in fungi, vertebrate, and plant [29-34]. In addition, Arabidopsis RanGAP1 is a continuous marker of the plane of cell division. It is concentrated at the PPB and retained in the CDZ, as well as at the growing edge of the cell plate and the phragmoplast $[25,34,35]$. Its localization in these positions suggests that small GTPase may have a role in the plant cell cycle.

The PPB is destroyed at the end of prophase or at the beginning of early prometaphase before the cell cycle enters metaphase. Metaphase can be divided into prometaphase and late metaphase, and prometaphase can be further divided into early and late prometaphase. In BY-2 cells and some other highly differentiated cells, the actin arrays in the cortex change after PPB destruction. After destruction of the PPB, the PPB-like band of MFs disappears at early prometaphase. Soon after the destruction of the PPB-like MFs, a break in the cortical MFs known as an actin-depleted zone (ADZ) forms at the exact position at which the PPB disappeared. This occurs in late prometaphase, and persists until early telophase [36,37]. The ADZ also acts as a marker of the position where the new cell wall will form, as if it replaces the function of PPB. From G2 to M phase, another structure known as the phragmosome appears. The intracellular cytoplasm supports the mitotic apparatus during $\mathrm{M}$ phase [38]. The phragmosome appears earlier than the PPB, and persists until the end of $\mathrm{M}$ phase; therefore, it may act as a bridge connecting the PPB and the ADZ. ADZ is a typical actin missing band in mitosis. An inhibitor of actin polymerization, BA, was added to the cell before the time of ADZ appearance could destroy normal cell-plate guidance, leading to formation of abnormal cell walls with distorted wall edges. This maybe brought about by the loss of "memories" of future division site where ADZ was located [5]. However, Sano et al. [39] reported that they found a structure named MF "twin peaks" (MFTP) instead of finding the ADZ, in the tobacco BY-2 cell line BY-GF11, a stably transformed line expressing a GFP-fABD2 MFs marker was observed over time and revealed that the structure of the MFs at the cell cortex during mitosis was in the form of two bands. This form of MF distribution was designated as MF "twin peaks". The MFTP originating from the broad band of MFs at late prometaphase would function as a marker of cytokinesis. The cell plate goes on to form in the exact location of the valley between the MFTP $[39,40]$.

\section{Roles of the actin cytoskeleton and its upstream signals in spindle formation and positioning}

In interphase, the actin cytoskeleton exhibits a dense meshwork structure. However, from late $\mathrm{G} 2$ phase to cytokinesis, the actin cytoskeleton undergoes successive rearrangements
[2]. The overall level of actin-bundling appears weak during the progression of cell division in the cortex [10]. The size and number of cortical and trans-cytoplasmic actin bundles is markedly reduced compared with interphase cells [3]. The breakdown of nuclear membranes, which is facilitated by the dissociation of the actin cytoskeleton, marks the entry of the cell into mitosis. During metaphase, actin filaments (or MFs) are observed in the spindle, linking the spindle to the cortex and forming a cage-like structure that wraps around the spindle, possibly functioning to hold the spindle in the correct axis in cell during metaphase [41]. Although the function of the MTs is more dominant than that of MFs during metaphase, the MFs and their factors are also necessary for metaphase spindle construction. A unique plant actin-binding protein (ABP) in Arabidopsis, AtFormin14 (AtFH14), which is localized to the spindle in metaphase, acts as a linking protein between microtubules and microfilaments to make the spindle functional in metaphase. The mutant line of AtFH14 in Arabidopsis is severely defective in male gametophyte development and leads to low pregnancy rate partly because of the abnormally shaped spindle in metaphase. Overexpressing AtFH14-GFP in tobacco BY-2 cells also leads to failure of turnover of spindles and phragmoplasts. These findings indicate that the actin cytoskeleton and ABP have an important role in the cell cycle [42].

Apart from the classical ABP, small GTPase proteins such as Ran have important roles in metaphase, too [43]. It is well accepted that animal cells contain centrosomes. However, plant cells lack these central microtubule nucleators [41]. Instead, their microtubules are nucleated at a variety of surfaces including the nuclear envelope and the cell cortex [44]. It was observed that the GTP-bound form of Ran can stimulate microtubule polymerization, thus driving spindle assembly [45-47]. During M phase, the high concentration of Ran-GTP located exclusively in the vicinity of chromosomes can release tubulin polymerization factors such as Targeting Protein for Xklp2 (TPX2) from their blockers in vertebrate cells. This event serves as the initial positional cue for spindle formation in the absence of centrosomes [48]. A plant TPX2-like protein was also found in Arabidopsis. It was able to nucleate microtubules, and relied on Ran for its shuffle between the nucleus and the cytoplasm [49,50]. Besides organizing microtubules, in vertebrate cells, Ran is also needed for the alignment of chromosomes at the metaphase plate. Furthermore, the Ran pathway is required for other events in postmetaphase, including chromosome segregation and microtubule midbody assembly [51]. Whether a similar mechanism exists in plant cells remains unknown [52].

\section{Dynamics of actin cytoskeleton in anaphase}

Anaphase can be categorized into two phases; early anaphase 
and late anaphase. In early anaphase, spindle microtubules suddenly become more stable. However, the regulatory mechanisms involved in this change of microtubule behavior, and the significance of this change for chromosome segregation, are remain unclear [51,53-55]. The existence of late anaphase, the phase at which approximately $40 \%$ of the total separation of chromosomes has been completed, was clarified in tobacco BY-2 cells using fluorescent proteins and image analyses [56]. Late anaphase, a period that can be referred to as the anaphase-telophase transition, was also studied in isolated plant endosperm cells of Blood Lily. In that system, a new population of actin filaments appeared at the equator and contributed to the formation of the cell plate before the formation of the microtubular phragmoplast [57]. The same phenomenon was also observed in BY-2 cells: after the separation of sister chromosomes, two bands of MFs formed parallel to each other at the site of initiation of the phragmoplast, then, the distance between the two bands decreased and the phragmoplast formed close to the bands [58]. The new cell plate would appear between the two bands [19]. Hence, it is clear that the actin cytoskeleton is required for the correct formation of the phragmoplast. Actin filaments of the phragmoplast are quite short, and it is unknown whether they are synthesized in this short format or whether they are cleaved into shorter pieces after being polymerized into long filaments [40]. Maybe ABPs have significant roles in controlling microfilaments behavior in anaphase. Then, the cortical actin network stretches along the spindle during chromosome migration in anaphase, and remains homogeneous during this process. Inhibition of anaphase with Colchicine, which changes actin distribution in cell, did not arrest chromosome movement [59]. For this reason, we can conclude that the F-actin-microtubule interaction, as well as other factors, may contribute to the separation and movement of chromosomes together, but actin itself alone does not have such a decisive role.

\section{Roles of phragmoplast actin filaments in cell plate formation during telophase and cytokinesis}

In telophase and cytokinesis, the actin filaments reorganize into regular arrays to complete the last steps of one cell cycle. As animal cells have a contractile ring formed by actin filaments, in higher plants cells there is a specialized structure named phragmoplast, which appears in late anaphase and assists in the construction of the new cell wall $[60,61]$. The mechanisms underlying the initiation of the phragmoplast are not clear. The phragmoplast MTs originate alongside the remaining kinetochore MTs in the midzone during late anaphase, then increase in number and consolidate into two short bundles with their plus ends overlapping under various kinds of factors, such as MAPs, MACs (putative cross-linker between microtubules and actin filaments), and
bKRPs (bipolar kinesin-related protein) [62]. With the merging of the first several vesicles, the new cell plane begins to form. As the new cell plane elongating, two parallel bundles, each made up of microtubules and actin filaments with their plus ends facing the nascent cell plate, form the phragmoplast. Here, the MFs in cooperation with myosin transport vesicles containing materials for cell wall synthesis. In budding yeast, class $\mathrm{V}$ myosins are involved in the transport of membrane-bound vesicles, organelles, and RNAs from the mother cell to the daughter cell [63]. For this ability of Myosin, it has been found in the phragmoplast [64]. In the elongation period of the phragmoplast, condensed MFs and MTs localize at the edge of the new cell plane, implying that these two factors function together in helping the rapid elongation of the cell plane. Newly arriving vesicles are targeted to the lateral margin of the cell plate, resulting in its expansion outward to the parental plasma membrane. Golgi stacks accumulate near the plane of division, forming a "Golgi belt" [65]. It is reasonable to conclude that Golgiderived vesicles containing materials for the construction of the new cell wall are delivered by the phragmoplast to the division plane. Membranes in the margin of the cell plane first form a tubular structure, and then merge into a planar two-layered membrane, with callose between the new membranes becoming the new cell wall [49]. In BY-2 cells and Arabidopsis root cells, many ABPs were found to colocalize in the phragmoplast. AtFH14, which was also located in the spindle in metaphase, may have a role in the initiation and elongation of the phragmoplast in Arabidopsis due to its function of crosslinking MTs and MFs [42]. AtFormin8 (AtFH8), another plant formin that can bind MFs, was more concentrated in edge of the newly formed cell plane as well as the new cell wall after cytokinesis [66]. However, the detailed mechanism by which it functions in the cooperation of MFs and vesicles for cell plane formation remains elusive. In addition, it remains unclear why it is retained in the new cell wall after cytokinesis. The same phenomena were found in AtFormin6 (AtFH6); AtFH6-GFP fluorescence appeared exclusively at the periphery of the cell, and therefore, may be associated with the plasma membrane. These proteins harbor an $\mathrm{N}$-terminal signal sequence followed by a transmembrane domain, which could target them to the secretory system $[67,68]$. This may imply that ABPs adjust MFs and the secretory system to assure formation of the new cell wall. Ingouff et al. [69] reported that AtFormin5 (AtFH5) was localized to the cell plate of dividing root cells of Arabidopsis. Two atfh5 insertional mutant lines showed compromised cytokinesis in the endosperm cells.

The small GTPase families are a group of regulators with prominent functions in the cell cycle. The ARF family and its associated proteins including ARF-GEFs and ARF-GAP are required for the vesicles budding and trafficking pathway [70,71]. AtRanGAP1 localizes at the edge of newly formed cell plane [25], which may imply that AtRanGAP1 
functions in the transportation and merging of the vesicles into the new cell plane. This is consistent with its localization in PPB, which guides the direction of growth of the new cell plane [34]. Therefore, small GTPases may cooperate with their regulators, such as the cytoskeleton, to determine the site of division and cell wall formation. In late telophase, the expanding phragmoplast interacts with the mother cell cortex to attach the cell plate at the cortical division site, which is marked by the PPB at preprophase [71]. The fusion of the cell plate with the parental plasma membrane is a complicated process that can be divided into two events: the recognition of the correct contact site, and the maturation of the new cell wall. These two events are strongly related. Classic experiments have demonstrated that when the expanding cell plate was forced experimentally to attach to the mother cell surface somewhere rather than the cortical division site, the new cell wall failed to mature normally. This observation suggested that the interaction of the cell plate with the correct cortical division site or adjacent cell wall promotes proper wall maturation [72-74]. Thus, there is a feedback signal in the contact process to accurately control the formation of new cells. The members of this pathway should be further studied. Two proteins, AIR9 and TPLATE, were reported to participate in the process. In Arabidopsis, the TPLATE mutant line showed disoriented and incomplete cell walls. In BY-2 cells, TPLATE knock down caused cell plates to have diffuse edges that did not attach properly to the mother cell [72]. After finish of the new cell wall growth, two new daughter cells come into being, and next cell cycle would proceed as before.

\section{Conclusions and perspectives}

Different cytoskeletal structures, i.e., the plant-specific PPB bands, the spindles, and the plant-specific phragmoplast, appear at different stages of mitosis. For the further clear understanding of these cytoskeleton arrays in the cell cycle, we made a diagram (Figure 1) to show the easy characteristics of the cytoskeletons, especially actin filaments. The main roles of actin filaments are to serve as a scaffold for the fixation of certain cell apparatus, as a bridge for transporting vesicles to certain places, as a framework to help organize mitotic devices, and as an auxiliary tool for the cell to divide into two at the right place. As model systems, Arabidopsis and the tobacco BY-2 cell line have provided us with many results. Important results have also been obtained by using anti-cytoskeleton drugs. All of these findings indicate the importance of the actin cytoskeleton in the cell cycle as well as some factors regulating the actin cytoskeleton, such as ABPs. Small GTPases also have an important role in cell cycle progression: the members of these families may be multi-functional because of their property as a molecular switch and small molecular weight to ease of transport within the cell. However, further research should focus on the signaling pathway that connects these factors (a)

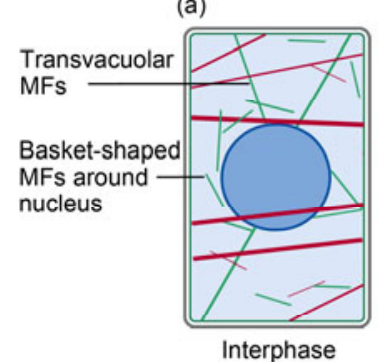

(e) (b)

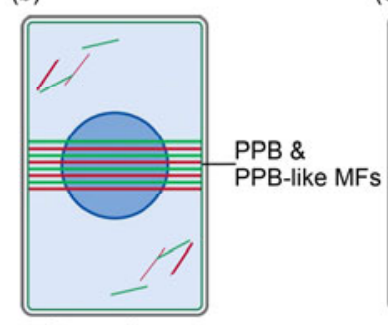

Preprophase (c)

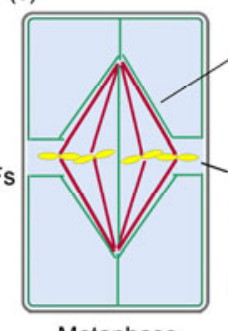

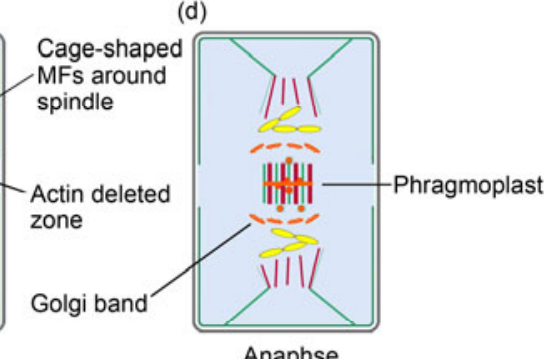

(g)

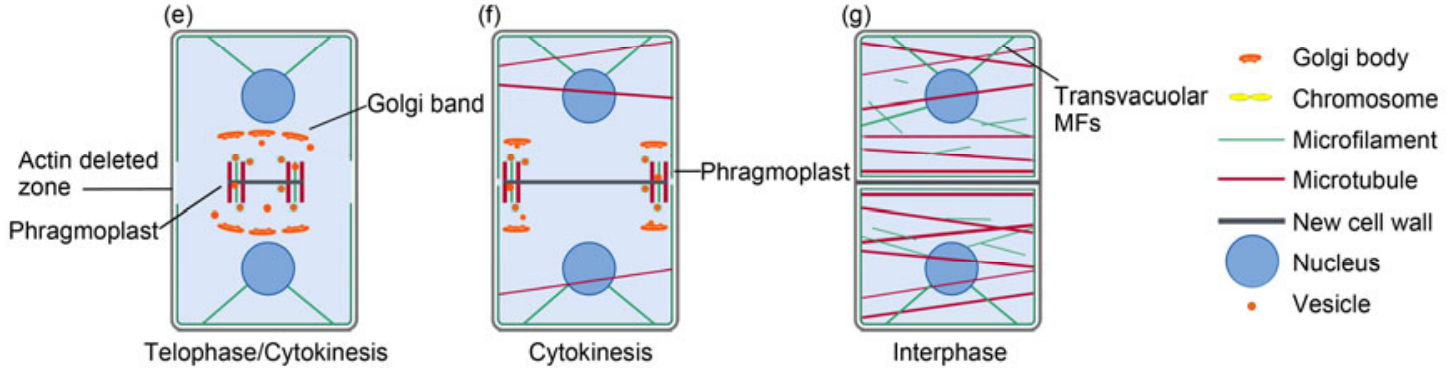

Figure 1 The typical cytoskeleton arrays appeared in every phase during one classical cell cycle. Microfilament is showed in green straight line; microtubule is showed in red straight line. As it shows in (a), in interphase, short MFs form the basket-like structure around nucleus, some other bundling microfilaments form transvacuolar MFs connecting nucleus and cortex. In preprophase, in (b), MFs form PPB-like actin ring in parallel with PPB in the cell, maybe deciding the future cell division site. In (c), cell enters metaphase; MFs form a cage shape that wraps the spindle, holding the spindle in the right axis. In cortex, an actin-deleted zone is appeared just as PPB, suggesting the future division site. (d)-(f) shows the typical plant specific apparatus-phragmoplast. Phragmoplast shows up in late anaphase, exists in telophase and cytokinesis, helping the construction and position of the new cell wall. It is made up by short MFs and MTs as well as Golgi vacuoles and newly formed cell wall. (g) shows the new formed two sister cells, with the same MFs arrays as interphase. 
to their cell-cycle targets, including cytoskeleton, kinases, ABPs, MAPs, and cyclins. In conclusion, there is still much to learn about how the cytoskeleton controls the cell cycle. In-depth analyses of cell cycle regulation will shed new light on cell biology research.

This work was supported by the National Natural Science Foundation of China (30870211, 30970174), the National Basic Research Program of China (2007CB108700) and the Chinese Transgenic Project (2009ZX08009-059B) to H. Ren.

1 Thomas C, Tholl S, Moes D, et al. Actin bundling in plants. Cell Motil Cytoskel, 2009, 66: 940-957

2 Heng Y W, Koh C G. Actin cytoskeleton dynamics and the cell division cycle. Int J Biochem Cell Biol, 2010, 42: 1622-1633

3 Nakaseko Y, Yanagida M. Cytoskeleton in the cell cycle. Nature, 2001, 412: 291-292

4 Pollard T D, Cooper J A. Actin, a central player in cell shape and movement. Science, 2009, 326: 1208-1212

5 Hoshino H, Yoneda A, Kumagai F, et al. Roles of actin-depleted zone and preprophase band in determining the division site of higher-plant cells, a tobacco BY-2 cell line expressing GFP-tubulin. Protoplasma, 2003, 222: 157-165

6 Yu M, Yuan M, Ren H. Visualization of actin cytoskeletal dynamics during the cell cycle in tobacco (Nicotiana tabacum L. cv Bright Yellow) cells. Biol Cell, 2006, 98: 295-306

7 Buschmann H, Green P, Sambade A, et al. Cytoskeletal dynamics in interphase, mitosis and cytokinesis analysed through Agrobacteriummediated transient transformation of tobacco BY-2 cells. New Phytol, 2011, 190: 258-267

8 Voigt B, Timmers A C J, Sămaj J, et al. GFP-FABD2 fusion construct allows in vivo visualization of the dynamic actin cytoskeleton in all cells of Arabidopsis seedlings. Eur J Cell Biol, 2005, 84: 595-608

9 Buschmann H, Lloyd C W. Arabidopsis mutants and the network of microtubule-associated functions. Mol Plant, 2008, 1: 888-898

10 Traas J A, Doonan J H, Rawlins D J, et al. An actin network is present in the cytoplasm throughout the cell cycle of carrot cells and associates with the dividing nucleus. J Cell Biol, 1987, 105: 387-395

11 Gachet Y, Tournier S, Millar J B A, et al. AMAP kinase-dependent actin checkpoint ensures proper spindle orientation in fission yeast. Nature, 2001, 412: 352-355

12 Lee K, Song K. Actin dysfunction activates ERK1/2 and delays entry into mitosis in mammalian cells. Cell Cycle, 2007, 6: 1487-1495

13 Pickett-Heaps J D, Northcote D H. Organization of microtubules and endoplasmic reticulum during mitosis and cytokinesis in wheat meristems. J Cell Sci, 1966, 1: 109-120

14 Pickett-Heaps J D. Preprophase microtubules and stomatal differentiation; some effects of centrifugation on symmetrical and asymmetrical cell division. J Ultrastruct Res, 1969, 27: 24-44

15 Eleftheriou E P, Palevitz B A. The effect of cytochalasin D on preprophase band organization in root tip cells of Allium. J Cell Sci, 1992, 103: 989-998

16 Mineyuki Y. The preprophase band of microtubules: Its function as a cytokinetic apparatus in higher plant cells. Int Rev Cytol, 1999, 187: $1-49$

17 Richards T A, Cavalier-Smith T. Myosin domain evolution and the primary divergence of eukaryotes. Nature, 2005, 436: 1113-1118

18 Panteris E. Cortical actin filaments at the division site of mitotic plant cells: A reconsideration of the 'actin-depleted zone'. New Phytol, 2008, 179: 334-341

19 Van Damme D. Division plane determination during plant somatic cytokinesis. Curr Opin Plant Biol, 2009, 12: 745-751

20 Dhonukshe P, Gadella T W J. Alteration of microtubule dynamic instability during preprophase band formation revealed by yellow fluorescent protein-CLIP170 microtubule plus-end labeling. Plant Cell,
2003, 15: 597-611

21 Marcus A I, Dixit R, Cyr R J. Narrowing of the preprophase microtubule band is not required for cell division plane determination in cultured plant cells. Protoplasma, 2005, 226: 169-174

22 Azimzadeh J, Nacry P, Christodoulidou A, et al. Arabidopsis TONNEAU1 proteins are essential for preprophase band formation and interact with centrin. Plant Cell, 2008, 20: 2146-2159

23 Camilleri C, Azimzadeh J, Pastuglia M, et al. The Arabidopsis TONNEAU2 gene encodes a putative novel protein phosphatase $2 \mathrm{~A}$ regulatory subunit essential for the control of the cortical cytoskeleton. Plant Cell, 2002, 14: 833-845

24 Wright A J, Gallagher K, Smith L G. Discordia1 and alternative discordia1 function redundantly at the cortical division site to promote preprophase band formation and orient division planes in maize. Plant Cell, 2009, 21: 234-247

$25 \mathrm{Xu}$ X M, Zhao Q, Rodrigo-Peiris T, et al. RanGAP1 is a continuous marker of the Arabidopsis cell division plane. Proc Natl Acad Sci USA, 2008, 105: 18637-18642

26 Gaillard J, Neumann E, Van Damme D, et al. Two microtubule-associated proteins of Arabidopsis MAP65s promote antiparallel microtubule bundling. Mol Biol Cell, 2008, 19: 4534-4544

27 Walker K L, Müller S, Moss D, et al. Arabidopsis TANGLED identifies the division plane throughout mitosis and cytokinesis. Curr Biol, 2007, 17: 1827-1836

28 Müller S, Han S, Smith L G. Two kinesins are involved in the spatial control of cytokinesis in Arabidopsis thaliana. Curr Biol, 2006, 16: 888-894

29 Hopper A K, Traglia H M, Dunst R W. The yeast RNA1 gene product necessary for RNA processing is located in the cytosol and apparently excluded from the nucleus. J Cell Biol, 1990, 111: 309-321

30 Melchior F, Weber K, Gerke V. A functional homologue of the RNA1 gene product in Schizosaccharomyces pombe: Purification, biochemical characterization, and identification of a leucine-rich repeat motif. Mol Biol Cell, 1993, 4: 569-581

31 DeGregori J, Russ A, von Melchner H, et al. A murine homolog of the yeast RNA1 gene is required for postimplantation development. Gene Dev, 1994, 8: 265-276

32 Bischoff F R, Krebber H, Kempf T, et al. Human RanGTPase-activating protein RanGAP1 is a homologue of yeast Rna1p involved in mRNA processing and transport. Proc Natl Acad Sci USA, 1995, 92: 1749-1753

33 Meier I. A novel link between ran signal transduction and nuclear envelope proteins in plants. Plant Physiol, 2000, 124: 1507-1510

34 Pay A, Resch K, Frohnmeyer H, et al. Plant RanGAPs are localized at the nuclear envelope in interphase and associated with microtubules in mitotic cells. Plant J, 2002, 30: 699-709

35 Jeong S Y, Rose A, Joseph J, et al. Plant-specific mitotic targeting of RanGAP requires a functional WPP domain. Plant J, 2005, 42: 270-282

36 Liu B, Palevitz B A. Organization of cortical microfilaments in dividing root cells. Cell Motil Cytoskel, 1992, 23: 252-264

37 Yoneda A, Akatsuka M, Hoshino H, et al. Decision of spindle poles and division plane by double preprophase bands in a BY-2 cell line expressing GFP-tubulin. Plant Cell Physiol, 2005, 46: 531-538

38 Sinnott E W, Bloch R. Division in vacuolate plant cells. Am J Bot, 1941, 28: 225-233

39 Sano T, Higaki T, Oda Y, et al. Appearance of actin microfilament 'twin peaks' in mitosis and their function in cell plate formation, as visualized in tobacco BY-2 cells expressing GFP-fimbrin. Plant J, 2005, 44: 595-605

40 Higaki T, Sano T, Hasezawa S. Actin microfilament dynamics and actin side-binding proteins in plants. Curr Opin Plant Biol, 2007, 10: 549-556

41 Kunda P, Baum B. The actin cytoskeleton in spindle assembly and positioning. Trends Cell Biol, 2009, 19: 174-179

42 Li Y, Shen Y, Cai C, et al. The type II Arabidopsis formin 14 interacts with microtubules and microfilaments to regulate cell division. Plant Cell, 2010, 22: 2710-2726

43 Hetzer M, Gruss O J, Mattaj I W. The Ran GTPase as a marker of 
chromosome position in spindle formation and nuclear envelope assembly. Nat Cell Biol, 2002, 4: 177-184

44 Ehrhardt D W. Straighten up and fly right-Microtubule dynamics and organization of noncentrosomal arrays in higher plants. Curr Opin Cell Biol, 2008, 20: 107-116

45 Bischoff F R, Klebe C, Kretschmer J, et al. RanGAP1 induces GTPase activity of nuclear Ras-related Ran. Proc Natl Acad Sci USA, 1994, 91: 2587-2591

46 Bischoff F R, Krebber H, Smirnova E, et al. Co-activation of RanGTPase and inhibition of GTP dissociation by Ran-GTP binding protein RanBP1. EMBO J, 1995, 14: 705-715

47 Ohtsubo M, Okazaki H, Nishimoto T. The $\mathrm{RCC} 1$ protein, a regulator for the onset of chromosome condensation locates in the nucleus and binds to DNA. J Cell Biol, 1989, 109: 1389-1397

48 Kahana J A, Cleveland D W. Beyond nuclear transport: Ran-GTP as a determinant of spindle assembly. J Cell Biol, 1999, 146: 1205-1209

49 Vos J W, Pieuchot L, Evrard J L, et al. The plant TPX2 protein regulates prospindle assembly before nuclear envelope breakdown. Plant Cell, 2008, 20: 2783-2797

50 Ciciarello $M$, Mangiacasale $R$, Thibier $C$, et al. Importin $\beta$ is transported to spindle poles during mitosis and regulates Ran-dependent spindle assembly factors in mammalian cells. J Cell Sci, 2004, 117: 6511-6522

51 Mallavarapu A, Sawin K, Mitchison T. A switch in microtubule dynamics at the onset of anaphase B in the mitotic spindle of Schizosaccaromyces pombe. Curr Biol, 1999, 9: 1423-1428

52 Canaday J, Stoppin-Mellet V, Mutterer J, et al. Higher plant cells: Gamma-tubulin and microtubule nucleation in the absence of centrosomes. Microsc Res Techniq, 2000, 49: 487-495

53 Maddox P S, Bloom K S, Salmon E D. The polarity and dynamics of microtubule assembly in the budding yeast Saccharomyces cerevisiae. Nat Cell Biol, 2000, 2: 36-41

54 Kline-Smith S L, Walczak C E. Mitotic spindle assembly and chromosome segregation: Refocusing on microtubule dynamics. Mol Cell, 2004, 15: 317-327

55 Zhai Y, Kronebusch P J, Borisy G G. Kinetochore microtubule dynamics and the metaphase-anaphase transition. J Cell Biol, 1995, 131: $721-734$

56 Tomomi H, Toshio S, Natsumaro K, et al. Contribution of anaphase $\mathrm{B}$ to chromosome separation in higher plant cells estimated by image processing. Plant Cell Physiol, 2007, 48: 1509-1513

57 Schmit A C, Lambert A M. Microinjected fluorescent phalloidin in vivo reveals the F-actin dynamics and assembly in higher plant mitotic cells. Plant Cell, 1990, 2: 129-138
58 Zhang Y, Zhang W, Baluska F, et al. Dynamics and roles of phragmoplast microfilaments in cell plate formation during cytokinesis of tobacco BY-2 cells. Chinese Sci Bull, 2009, 54: 2051-2061

59 Schmit A C, Lambert A M. Plant actin filament and microtubule interactions during anaphase-telophase transition: Effects of antagonist drugs. Biol Cell, 1988, 64: 309-319

60 Cleary A L, Gunning B E S, Wasteneys G O, et al. Microtubule and F-actin dynamics at the division site in living Tradescantia stamen hair cells. J Cell Sci, 1992, 103: 977-988

61 Staehelin L A, Hepler P K. Cytokinesis in higher plants. Cell, 1996, 84: 821-824

62 Jürgens G. Cytokinesis in higher plants. Annu Rev Plant Biol, 2005, 56: 281-299

63 Pruyne D, Legesse-Miller A, Gao L, et al. Mechanisms of polarized growth and organelle segregation in yeast. Annu Rev Cell Dev Biol, 2004, 20: 559-591

64 Smith L G. Plant cell division: Building walls in the right places. Nat Rev Mol Cell Biol, 2001, 2: 33-39

65 Nebenführ A, Frohlick J A, Staehelin L A. Redistribution of Golgi stacks and other organelles during mitosis and cytokinesis in plant cells. Plant Physiol, 2000, 124: 135-151

66 Xue X H, Guo C Q, Du F, et al. AtFH8 is involved in root development under effect of low-dose latrunculin B in dividing cells. Mol Plant, 2011, 4: 264-278

67 Cvrcková F. Are plant formins integral membrane proteins? Genome Biol, 2000, 1: research001.1-001.7

68 Deeks M J, Hussey P J, Davies B. Formins: Intermediates in signaltransduction cascades that affect cytoskeletal reorganization. Trends Plant Sci, 2002, 7: 492-498

69 Ingouff M, Gerald J N F, Guérin C, et al. Plant formin AtFH5 is an evolutionarily conserved actin nucleator involved in cytokinesis. Nat Cell Biol, 2005, 7: 374-380

70 Kirchhausen T. Three ways to make a vesicle. Nat Rev Mol Cell Biol, 2000, 1: 187-198

71 Jürgens G, Pacher T. Cytokinesis: Membrane trafficking by default? Annu Plant Rev, 2003, 9: 238-254

72 Müller S, Wright A J, Smith L G. Division plane control in plants: New players in the band. Trends Cell Biol, 2009, 19: 180-188

73 Gunning B E S, Wick S M. Preprophase bands, phragmoplasts, and spatial control of cytokinesis. J Cell Sci Suppl, 1985, 2: 157-179

74 Mineyuki Y, Gunning B E S. A role for preprophase bands of microtubules in maturation of new cell walls, and a general proposal on the function of preprophase band sites in cell division in higher plants. J Cell Sci, 1990, 97: 527-537

Open Access This article is distributed under the terms of the Creative Commons Attribution License which permits any use, distribution, and reproduction in any medium, provided the original author(s) and source are credited. 